\title{
Torsion of bilobed testis and biopsy-proven ipsilateral supernumerary testis in an adolescent
}

\author{
Darren Beiko, MD, FRCSC, DABU; ${ }^{*}$ Andrew E. MacNeily, MD, FRCSC, FAAP'
}

\begin{abstract}
Testicular torsion in patients with polyorchidism is rare, with less than 20 cases being reported. Bilobed testis has only been reported once in the literature to date. We report an interesting case of polyorchidism with torsion of an ipsilateral bilobed testis. The abnormal looking bilobed infarcted testis was removed, but the smaller viable supernumerary testis was biopsied and preserved.
\end{abstract}

Can Urol Assoc J 2010;4(3):E67-E70

\section{Introduction}

This report represents an interesting case of biopsy-proven polyorchidism with torsion of an ipsilateral abnormal bilobed testis that was diagnosed intraoperatively during scrotal exploration for a suspected testicular torsion. Although testicular biopsy is rarely indicated in the pediatric population, we performed a biopsy of the supernumerary testis to establish the diagnosis by verifying normal seminiferous tubules and normal spermatogenesis. To the best of our knowledge, this is the first reported case of biopsyproven polyorchidism associated with testicular torsion of a bilobed testis.

\section{Case report}

A 13-year-old male adolescent presented to the emergency room with a 4-hour history of acute left-lower quadrant abdominal pain and left hemiscrotal pain. He had experienced several intermittent episodes of severe left-lower quadrant pain and left hemiscrotal pain over the preceding 2 months. He did not have any urinary or bowel symptoms, was not sexually active and did not have any fevers. During the clinical assessment, the pain subsided and physical examination revealed a normal testis positioned in its normal vertical axis without any significant tenderness. Initial scrotal ultrasound was somewhat confusing because it showed what appeared to be 2 different structures in the left hemiscrotum. The first structure measured $4.1 \times 2.2 \mathrm{~cm}$ and appeared to be a bilobed structure with echogenicity consistent with testicular tissue (Fig. 1a). More inferiorly, the second structure measured only $2.1 \times 1.2 \mathrm{~cm}$, but demonstrated the same echogenicity (Fig. 1b). Given the clinical findings, testicular torsion was ruled out and he was discharged with instructions to return to the emergency room if the testicular pain returned and follow-up plans for a repeat scrotal ultrasound in 1 to 2 weeks were made. He remained pain-free for 4 days, but then returned to the emergency room after experiencing increasing pain - this time with associated swelling. On repeat examination, the left hemiscrotum was found to be rock hard and exquisitely tender, which was concerning for testicular torsion. Repeat scrotal ultrasonography revealed a markedly hypoechoic bilobed testis with no blood flow (Fig. 1c) and informed consent was obtained for urgent scrotal exploration and possible orchiopexy or orchiectomy. Intraoperatively, testicular torsion of the bilobed testis was immediately evident (Fig. 2a, large arrow). The spermatic cord was immediately untwisted. There was also an ovoid $2 \mathrm{~cm}$ viable structure that resembled testicular tissue in its colour, consistency and shape (Fig. 2a, small arrow). This smaller structure was consistent with the structure identified in Fig. $1 \mathrm{~b}$ and had its own robust vascular stalk (Fig. 2b, arrow), without any epididymis or vas deferens. It was suspected to be a supernumerary testis, so a biopsy was performed to confirm the diagnosis. Seminiferous tubules protruded instantly once the tunica albuginea was incised, confirming our suspicion of a supernumerary testis. Given its gross normal appearance and its normal sonographic appearance, the decision was made to perform orchiopexy rather than orchiectomy. The infarcted bilobed testis was reassessed, but unfortunately it remained ischemic and orchiectomy was required. The contralateral testis was examined carefully and found to be normal. Therefore, an orchiopexy was performed. There were no intraoperative or postoperative complications and histopathology showed normal seminiferous tubules and spermatogenesis. The patient was well at 1-month follow-up. 


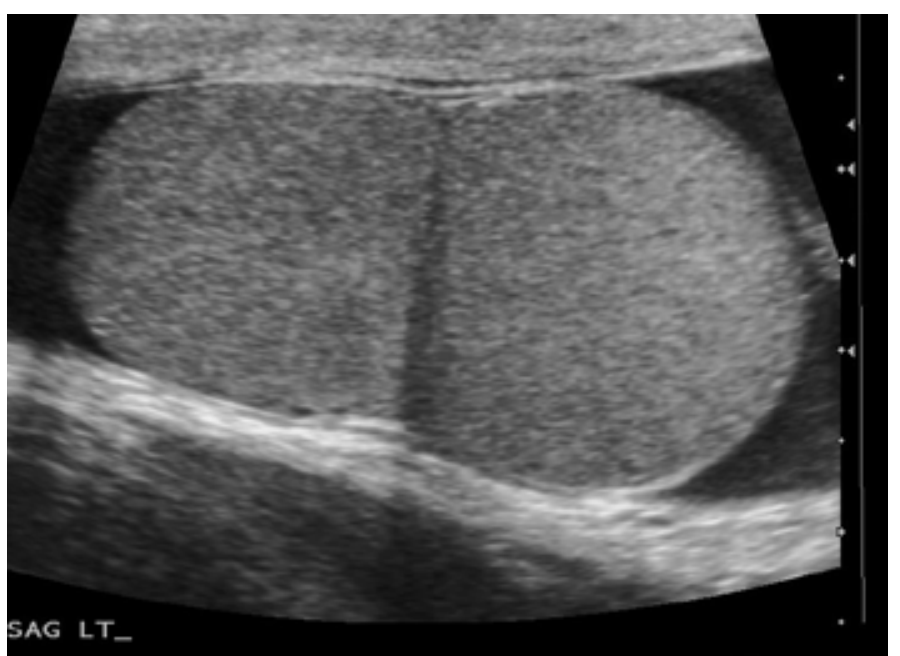

Fig. 1a. Ultrasound showing bilobed testis with normal echogenicity.

\section{Discussion}

Several terms have been used in the literature to describe an accessory or extra testis, including supernumerary testis, ${ }^{1-3}$ polyorchidism, ${ }^{4-13}$ testicular duplication, ${ }^{14,15}$ double testis ${ }^{16}$ and triorchidism. ${ }^{17-19}$ Polyorchidism is rare, with less than 100 cases reported to date, ${ }^{5}$ and is more common on the left side. ${ }^{20}$ Polyorchidism has been associated with several conditions including testicular cancer, ${ }^{6,8}$ cryptorchidism, ${ }^{7-15}$ inguinal hernia, ${ }^{13}$ hydrocele, ${ }^{13}$ infertility, $^{13}$ varicocele $^{1}$ and testicular torsion..$^{9-11}$ Testicular torsion is the most commonly reported associated condition. ${ }^{20}$

The exact cause of polyorchidism is not known. Several theories have been proposed, including anomalous appropriation of cells, initial longitudinal duplication of the genital ridge and transverse division of the genital ridge. ${ }^{5} \mathrm{~A}$ functional classification based upon the embryogenic development has been published by Mastroeni and colleagues. ${ }^{5}$

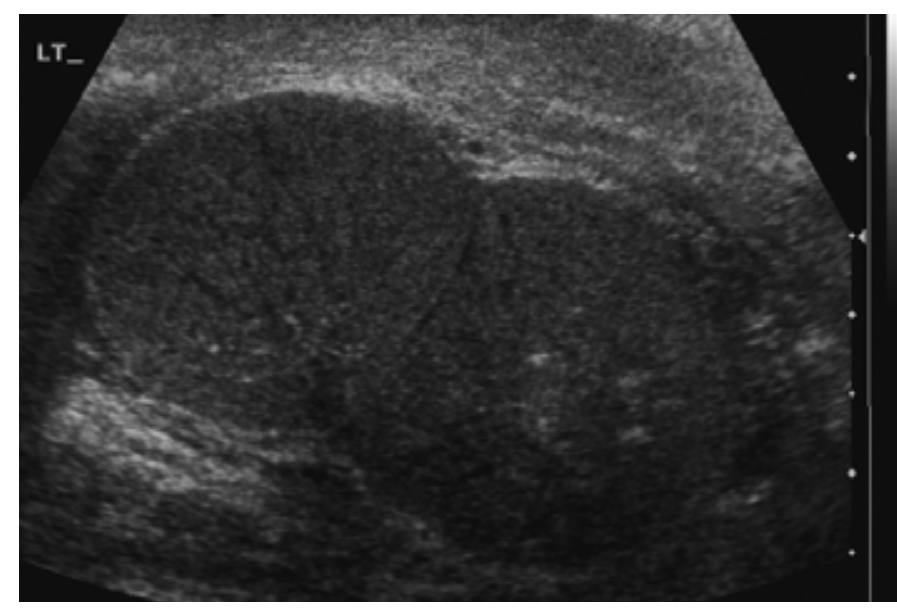

Fig. 1c. Ultrasound showing infarcted bilobed testis with marked hypoechogenicity.

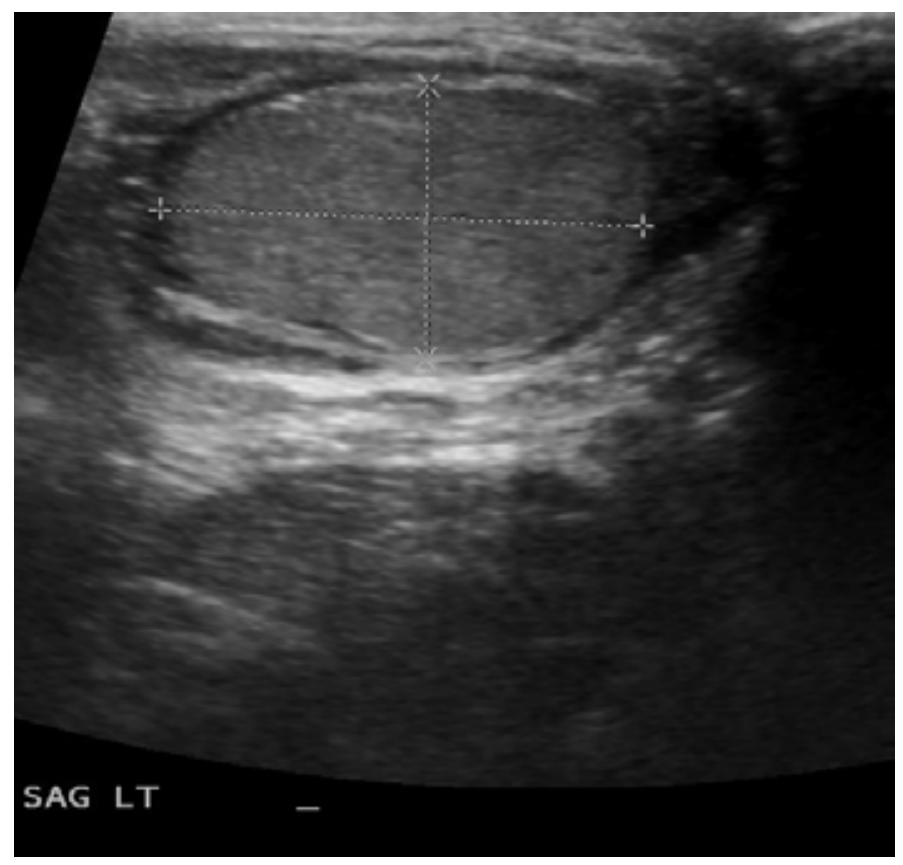

Fig. 1 b. Ultrasound showing accessory structure in left hemiscrotum, not yet diagnosed. Scrotal exploration and biopsy proved it to be a supernumerary testis.

In Type I polyorchidism, the supernumerary testis lacks an epididymis and vas. In Type II, the supernumerary testis is linked to the regular testis by a common epididymis and shares a common vas with it. In Type III, the supernumerary testis has its own epididymis but shares the vas with the regular testis. Our case demonstrated Type I polyorchidism, as the supernumerary testis lacked an epididymis and vas deferens, but had its own well-developed vascular stalk as seen in Fig. $2 \mathrm{~b}$.

Bilobed testis is another rare finding that makes this case even more interesting. In fact, McAlister and Manley are the only authors to report a case of bilobed testis to date. ${ }^{20}$ In their case, the adolescent patient presented with a palpable left testicular mass on physical examination and a scrotal ultrasound confirmed an abnormal testis, with the impression of a mass with a cleft in between it and the testis. Scrotal exploration revealed a bilobed testis and a biopsy was performed to rule out a tumour. Biopsy confirmed normal testicular tissue on both sides of the cleft, thus defining a bilobed testis. They acknolwleged that the cause was unknown at that time, but proposed that it may be the result of indentation of the urogenital ridge by peritoneal bands. ${ }^{20}$

Acute onset of testicular pain alone is a classic symptom of torsion and is sufficient to argue that our patient could have been explored on initial presentation without the need for ultrasound. However, the physical examination findings were not consistent with active torsion and the pain had subsided. This was the reason for our initial decision to not explore surgically. This decision was not related to the ultrasound-detected scrotal mass. Torsion-detorsion was the 


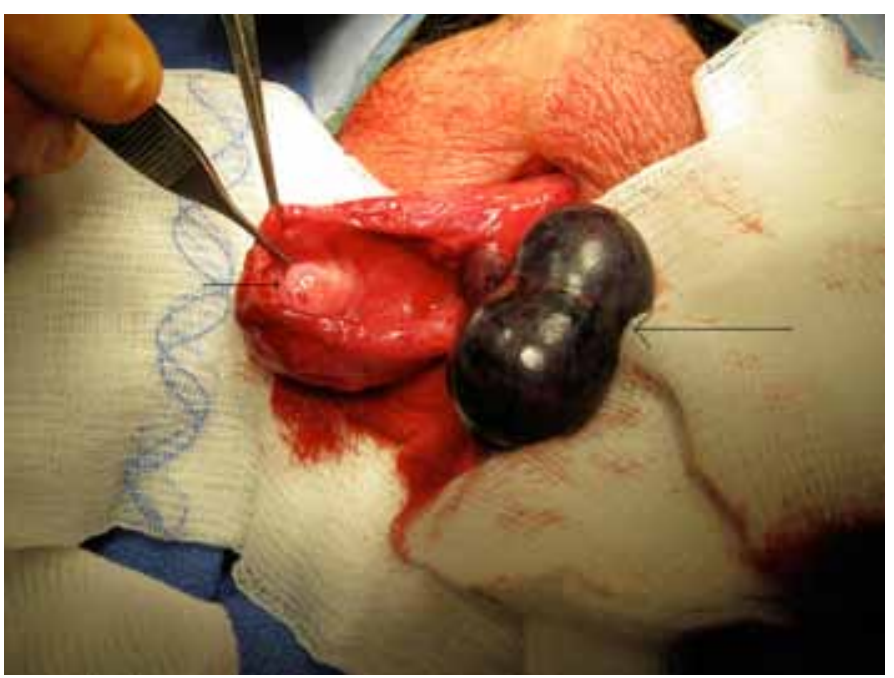

Fig. 2a. Intraoperative photograph showing infarcted bilobed testis (large arrow) and a well-perfused smaller supernumerary testis.

clinical diagnosis at that time. Ideally, one would perform early elective bilateral orchiopexy, but at our centre this would not have taken place in less than 1 week. The bilobed appearance of the testis and the accessory structure at the bottom of the scrotum were uncommon findings and the rationale behind a follow-up ultrasound in a few weeks was to obtain a scrotal ultrasound on an elective basis in absence of pain to better delineate the nature of the findings.

On second presentation, the history and physical examination were much more concerning for torsion and urgent scrotal exploration was indicated, without the need for a scrotal ultrasound. However, there was a 1-hour waiting period for access to the operating room due to another ongoing ' $A$ ' emergency case in the middle of the night. Although there was a delay in getting him to the operating table, the ultrasound itself did not contribute to this delay.

\section{Conclusion}

This report is unique because it involves 2 separate rare findings in the same hemiscrotum: torsion of a bilobed testis and a supernumerary testis. Furthermore, it illustrates a rare situation in which testicular biopsy may be performed in an adolescent during exploration for a suspected testicular torsion. de Buys Roessingh and colleagues recommended orchiectomy of a triorchid testis because of the risk of torsion. ${ }^{18}$ Khedis and colleagues reported that supernumerary testes are usually removed despite the fact that there is poor evidence in the literature supporting this. ${ }^{4}$ They therefore concluded that all uncomplicated cases of polyorchidism should be managed conservatively. We agree and did not feel that supernumerary orchiectomy was necessary in our case. Consequently, we performed orchiopexy of the polyorchid testis. Despite the fact that our patient lost the larger

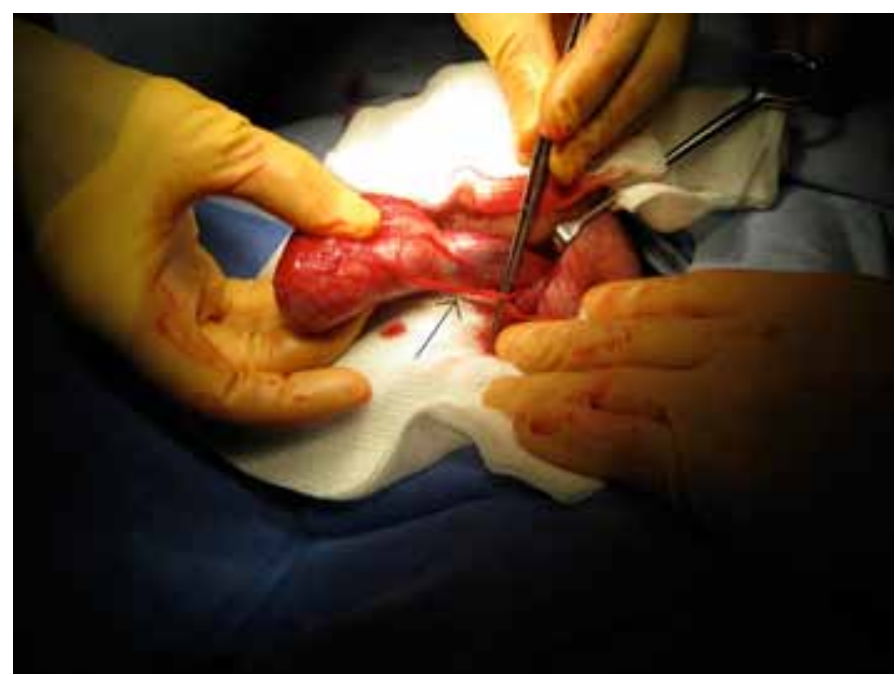

Fig. $\mathbf{2 b}$. Intraoperative photograph showing the intact vascular stalk of the supernumerary testis.

ipsilateral bilobed testis to torsion, he still has 2 intact testes. Both remaining testes should provide normal male hormonal function. However, due to the Type I polyorchidism in our patient, only the contralateral normal testis will contribute to future fertility potential because of the lack of epididymis and vas deferens. We conclude that radiologists and urologists diagnosing and treating scrotal disorders should be aware of supernumerary testis and its associated conditions.

*Assistant Professor, Department of Urology, Queen's University, Kingston General Hospital, Kingston, ON; ‘ Associate Professor, Department of Urologic Sciences, UBC, BC Children's Hospital, Vancouver, BC

Competing interests: None declared.

This paper has been peer-reviewed.

\section{References}

1. Mianne D, Martet G, Dran G, et al. Supernumerary testis and homolateral varicocele. Apropos of a case, study of spermatogenesis and review of the literature [in French]. J Urol (Paris) 1990;96:177-80.

2. Mewara PC, Babel AL, Gupta R, et al. Supernumerary testis with torsion. J Indian Med Assoc 1984;82:2068.

3. Steyaert M, De Sy W. Supernumerary testis and torsion of the spermatic cord [in French]. J Urol Nephrol (Paris) 1966;72:475-7.

4. Khedis M, Nohra J, Dierickx L, et al. Polyorchidism: presentation of 2 cases, review of the literature and a new management strategy. Urol Int 2008;80:98-101.

5. Mastroeni F, D'Amico A, Barbi E, et al. Polyorchidism: 2 case reports [in Italian]. Arch Ital Urol Androl 1997;69:319-22.

6. Thum G. Polyorchidism: case report and review of literature. J Urol 1991;145:370-2.

7. Gandia VM, Arrizabalaga M, Leiva 0 , et al. Polyorchidism discovered as testicular torsion associated with an undescended atrophic contralateral testis: a surgical solution. J Urol 1987;137:743-4.

8. Scott KW. A case of polyorchidism with testicular teratoma. J Urol 1980;124:930-1.

9. Shah SN, Miller BM, Geisler E. Polyorchidism discovered as testicular torsion. Urology 1992;39:543-4. 
10. Feldman S, Drach GW. Polyorchidism discovered as testicular torsion. J Urol 1983;130:976-7.

11. Ferro F, lacobelli B. Polyorchidism and torsion. A lesson from 2 cases. J Pediatr Surg 2005;40:1662-4.

12. Berger AP, Steiner H, Hoeltt L, et al. Occurrence of polyorchidism in a young man. Urology 2002;60:911.

13. Lawrentschuk N, MacGregor RJ. Polyorchidism: a case report and review of the literature. ANZ J Surg 2004;74:1130-2.

14. Wiedemann A, Jaussi R, Rabs U. Testicular torsion in testicular duplication. Kasuistik und Literaturubersicht [in German]. Urologe A 2005:44:162-5.

15. Kaibafzadeh AM. Bilateral duplication of undescended testes associated with testicular torsion. $\mathrm{Br} J$ Urol 1996:78:314-5.

16. Sözer IT, Kambero lu H, Yüceba E. Polyorchidism, bilateral double testis and unilateral testicular torsion. $\mathrm{Br} J \mathrm{Urol}$ 1989;64:546-7.
17. Tulchinsky M, Eggli DF. Scintigraphy of torsion in triorchidism. J Nucl Med 1992;33:1854-6.

18. de Buys Roessingh AS, El Ghoneimi A, Enezion G, et al. Triorchidism and testicular torsion in a child. J Pediatr Surg 2003;38:E13-E14.

19. Crawford DS, Bastable JR. Triorchidism with torsion. Br J Urol 1989;63:553-4.

20. McAlister WH, Manley CB. Bilobed testicle. Pediatr Radiol 1987;17:82.

Correspondence: Dr. Darren Beiko, Assistant Professor, Department of Urology, Queen's University, Kingston General Hospital, 76 Stuart St., Kingston, ON; fax: 613-545-1970 ; beikod@kgh.kari.net 